\title{
ADAPTIVITY IN E-LEARNING SYSTEMS
}

\author{
Romana OANCEA*, Vlad-Andrei BÂRSAN**, Iulian BOULEANU* \\ *“NicoaleBălcescu" Land Forces Academy, Sibiu, Romania \\ **"Lucian Blaga" University of Sibiu, Romania \\ oancea.romana@gmail.com, vlad.barsan@gmail.com, ibouleanu@gmail.com
}

\begin{abstract}
The differentiated designing of lessons from the virtual environment can have beneficial effects on the student. In order to achieve the objectives proposed in the course, the content should not only meet the student's expectations but must be designed adaptively according to the defining elements of each learner. Adaptability in content is an essential factor in maintaining motivation, involving the student, and engaging him/her in the study. The paper analyses approaches for the adaptive building of content by identifying the elements that can influence the achievement of the objectives - motivation, expectation, learner's style, a priori knowledge.
\end{abstract}

\section{Keywords: E-learning, adaptive learning, motivation, learner expectation}

\section{Introduction}

At present, when the graduate has to face the challenges of the labour market and technological progress is obvious, it is difficult to make the student, even from the early years of his studies, to study sustainably or to understand concepts and phenomena without which future understanding is not possible. In most cases, traditional classes are not enough for all students, due to their level of knowledge and different styles.

A blended learning approach is considered appropriate to reduce differences within the student group and furthermore combines the benefits of traditional learning with the benefits of learning in the virtual environment [1]. For on-line learning, however, the student must be motivated to spend some time in front of a device in order to reach the course objectives. The motivation is determined by several factors, namely [2]:

- Grab students' attention - if the reason why the student wants to improve his/her level of knowledge is not "strong" enough he/she will not be willing to study. Attention must be maintained throughout the course, not just in the start-up phase, so that a combination of visual elements, interactive or even gaming and challenging questions could stimulate the student.

- Engagement - student-cantered approach so that materials do not contain information that simply needs to be retained or taught, but to have a permanent accordance with real-life examples or effects in contents which could help increase motivation $[3,4]$. Involvement can be achieved by designing interactive scenarios to solve situations and analyze the effects of the student's own decisions.

- Interactivity [5] - Collaborative learning tools can be a real benefit in maintaining motivation for profiles that prefer to receive constant feedback or share concerns in the group.

The methods and tools offered by the virtual environment to maintain motivation are multiple - from gamification and 
augmented reality to micro learning or video learning, but the most important factor for student engagement, getting attention, and performance is the content [6]. More specifically, how it is structured both in terms of information and visibility, the degree of difficulty and the accessibility of lessons. Designing content by student profile requires using an adaptive approach.

\section{Adaptive learning}

Adaptive learning, using the Learning Management System and appropriate technology tools, refers to the content and the appropriate sequence in which content is approached to be modified or "adapted" for each learner [7]. Adaptive learning or the correct identification of students' needs and expectations, but also the achievement of the objectives for which the course was designed, requires the correct identification of a learner's profile, learner expectation, learner motivation $[8,9]$ but also learning knowledge or skills and efficiency in the learning process.

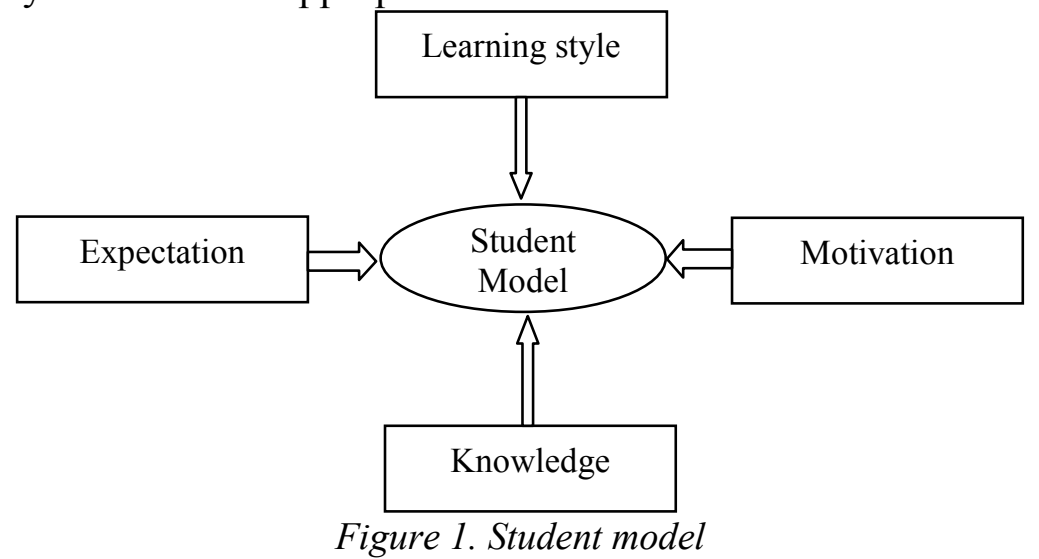

Learner's profile encompasses personal information, learning style and preferences. Felder \& Silverman [10] characterizes learning style according to four dimensions, depending on how information is processed and style is determined based on a set of 44 questions [11]:

- active vs. reflective - group work and work with materials are preferred, or work is preferable individually or in very small groups, and materials must be practical, to the point;

- sensing vs. intuitive - problems are resolved by following the classic algorithm/steps or are more creative and innovative;

- visual vs. verbal - information graphically represented as graphs, charts, images is easier to remember, instead, for the verbal style, written or presented information is better processed;

- sequential vs. global - progress is achieved in small, logical steps, in a well established order, instead a global learner uses a holistic process and the understanding occurs after there is a complete picture.

Kolb [12] describes the process of learner style as based on the preferences of each student, preferences due to the type of personality, specialization or career, but also to the environment in which he lives, and the developed model is characterized by four dimensions: concrete experience vs. abstract conceptualization, active experimentation vs. reflective observation. Each dimension is characterized by teaching materials and corresponding activities. If the concrete experience style prefers sets of problems, learning through examples, movies, simulations, in the abstract conceptualization style, thinking is analogical, obtained after the analysis and reading of conceptual works and the realization of complex projects. The active experimentation style teaches from case studies, examples or practical laboratory activities in contrast with the reflective observation style, where reflection is the keyword, based on questions, 
brainstorming, or discussions. In other words, during a class, approaches to the presentation of theoretical concepts, examples, exercises, and test quizzes or quizzes must be exposed differently, according to learner's style [13]. Adaptive content design, based on learner's style and level of knowledge, can motivate the student so that he/she will automatically trace the training and testing sequences. The motivation arises from the fact that it will not spend more time than it needs to learn information already known, and for presenting theories, practical examples of tasks, the approach is suited to the preferred style.

If initially, for adaptation, the approach was manual, lately there has been a focus on the automatic identification of style, knowledge and motivation to design the appropriate adaptive content for each individual, not at the class or group level [14]. The design of adaptive content and the instructional model should start from learner's profile, which is considered the basic component, and then design the learning objects so that the student achieves course objectives and implicitly achieves the required level of performance. In the traditional environment, for a class with not a large number of students, adaptive learning is hard to apply or requires a lot of effort from the teacher; instead a number of on-line platforms facilitate an adaptive approach.

\section{Designing content according to student preferences}

Starting from the prerequisites of the course - the student should be more than familiar with the elements studied in courses attended in previous years of studies, a pretest was designed which, on the one hand, would allow the learning style to be identified (visual versus verbal; sequential vs. global; abstract vs. concrete), and on the other hand to identify the level of knowledge gained a priori, essential knowledge for achieving the objectives.

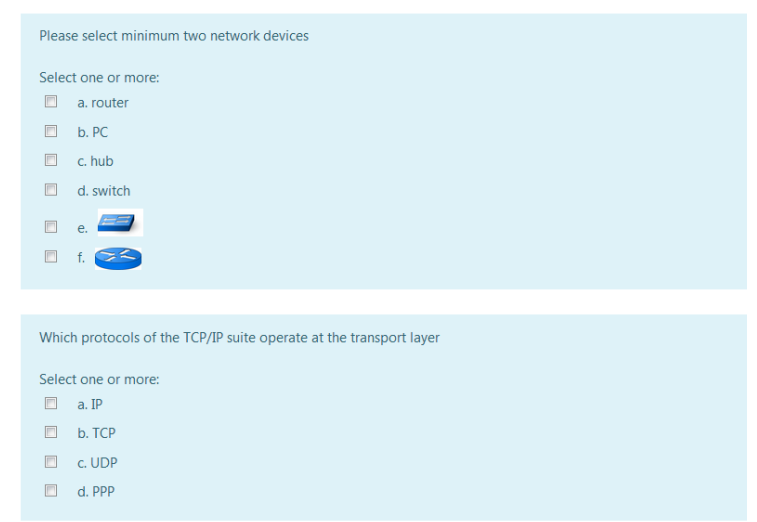

Figure 2 Example of Question for verifying knowledge

To determine the style, the questions were either direct - "Do you remember better if the information is displayed on the graph, or do you prefer the information to be shown in writing", or have been built so that style can be deduced.

The initial test was aimed at identifying the learning style, and then the form of presentation of the content and information was appropriately chosen according to the identified style. Multiple versions have been created for each learning object. For example, for a visual style, the content is video-oriented and infographic-oriented, while for a verbal style, the information is written or recorded. For a global learner an overview of the phenomenon was projected, while content for an analytical style has been designed in small steps with an emphasis on the elements that contribute to the overall picture.

As expected results the increase of motivation and sustained involvement is expected, and ultimately improvement of the level of knowledge for each student.

After designing the course in a learning management system, we will analyze the results obtained by students from several 
groups so that possible gaps can be analyzed.

\section{Conclusion}

Designing an adaptive content, according to individual preferences, can lead to visibly improved results, and students can become more motivated in what they do and can achieve the performance required by the teacher. Performance can only be achieved through sustained work, but the student does not feel overwhelmed by the amount of information, and the proper presentation of the content in accordance with each individual's style can make the study pleasant.

As a further development, to improve performance, it is intended that adaptability be determined after each set of questions, depending on the student's responses and attitudes within a short period of time, an attitude that can be influenced by various external factors, and the end of the course, to determine the level of satisfaction, the students will complete an end-of-course questionnaire, and the possible problems will be removed.

\section{References}

[1] Giurgiu Luminița, Bârsan Ghiță, Content Management Systems Viewed from a Behaviorism, Cognitivism, Constructivism \& Connectivism Perspective, 21ST International Conference the Knowledge-Based Organization, vol. 21, p. 688-693, Sibiu, 2015

[2] Pappas Christopher, 5 Tips to Enhance Motivation, eLearning industry, https://elearningindustry.com/5-tips-to-enhance-motivation-in-elearning

[3] Bârsan Ghiţă, Giurgiu Luminiţa, Sfârlog Benoni, Moşteanu Dan, e-Plasticity: an Asynchronous e-Learning Solution for Artillery Barrels Autofrettage Process, 8th European Conference on e-Learning, University of Bari, Bari, Italy on 29-30 October 2009, p. 52-59, ISBN 978-1-906638-52-8;

[4] Giurgiu Luminiţa, Bârsan Ghiţă, Moşteanu Dan, Educational Issues in Computer Based Assessment, 8th European Conference on e-Learning, University of Bari, Bari, Italy on 29-30 October 2009, pag. 228-235, ISBN 978-1-906638-52-8;

[5] Bolliger Doris U., Martindale Trey, Key Factors for Determining Student Satisfaction in Online Courses, International Journal on E-Learning, 3(1), 2004, p. 61-67;

[6] Giurgiu L., Microlearning - an envolving elearning trend, Land Forces Academy Scientific Bulletin, vol. 22 issue 1, 2017;

[7] Oxman, S., Wong, W., White paper: Adaptive learning systems. Integrated Education Solutions, 2014;

[8] Liyanage, M. P. P., Gunawardena, K. L., Hirakawa, M., Using Learning Styles to Enhance Learning Management Systems. International Journal on Advances in ICT for Emerging Regions ICTer, 7(2), 2014

[9] Burgos, D., Specht, M., Adaptive e-learning methods and IMS learning design: an integrated approach. In Advanced Learning Technologies, 2006. Sixth International Conference on IEEE, 2006, p. 1192-1193;

[10] Felder R.M., Silverman L.K., Learning and Teaching Styles In Engineering Education, Engineering Education, vol. 78 nr. 7, 1988, p. 674-681;

[11] https://www.webtools.ncsu.edu/learningstyles/

[12] Kolb, D.A., Experiential Learning: Experience as the Source of Learning and Development, Prentice-Hall, New Jersey, 1984;

[13] Milosevic D., Brkovic M., Bjekic D., Designing Lesson Content in Adaptive Learning Environments, Int. Journal of Emerging Technologies in Learning (iJET), vol. 2, nr. 1, 2006;

[14] Pham, Q. D., Florea, A. M., A method for detection of learning styles in learning management systems. UPB Scientific Bulletin, Series C: Electrical Engineering, 75(4), 2013. 